\title{
Periorbital Infection, CTCAE
}

National Cancer Institute

\section{Source}

National Cancer Institute. Periorbital Infection, CT CAE. NCI Thesaurus. Code C143748.

A disorder characterized by an infectious process involving the orbit of the eye. 